\title{
ANALISIS KELAYAKAN FINANSIAL PERIKANAN TANGKAP IKAN PELAGIS BESAR DI DESA TIAL KECAMATAN SALAHUTU KABUPATEN MALUKU TENGAH
}

\author{
Jahra Wasahua*, Eryka Lukman* \\ * Staf Pengajar MSP, FPIK UNIDAR-AMBON, e-mail: jahwasahua_83@yahoo.co.id
}

\begin{abstract}
ABSTRAK
Pemanfaatan sumberdaya ikan pelagis besar di Desa Tial menggunakan unit penangkapan pancing tonda dan pancing tegak. Penelitian ini bertujuan untuk menganalisis kelayakan usaha perikanan tangkap ikan pelagis besar di Desa Tial Kecamatan Salahutu Kabupaten Maluku Tengah. Metode yang digunakan adalah metode deskriptif analitis. Analisis data menggunakan analisis finansial dengan kriteria investasi, yaitu Net Present Value (NPV), Net Benefit-Cost ratio, Internal Rate of Return, dan Payback Periods. Hasil analisis finansial dengan discount factor $10 \%$ menunjukan usaha penangkapan ikan pelagis besar di Desa Tial dengan alat tangkap pancing tegak nilai NPV nya Rp. 7.263.992.073,37, Net B/C ratio 8,32, IRR 38,15\% dan Payback period 1 tahun 3 bulan. Sedangkan usaha alat tangkap pancing tonda nilai NVP nya $R p .1 .012 .791 .527,69$, Net B/C ratio 1,16, IRR $34,11 \%$ dan Payback period 1 tahun 1 bulan. Berdasarkan hasil analisis menunjukan usaha penangkapan ikan pelagis besar di Desa Tial layak untuk diteruskan baik dari sisi NPV, Net B/C Ratio, Internal Rate of Return, dan payback periods.
\end{abstract}

Kata Kunci: Kelayakan, Ikan Pelagis Besar, NPV, Net B/C Ratio

\section{PENDAHULUAN}

Maluku Tengah merupakan salah satu kabupaten di Provinsi Maluku yang memiliki potensi perikanan tangkap yang sangat besar. Jenis ikan yang potensinya cukup besar di Perairan Maluku Tengah adalah ikan pelagis besar. Potensinya mencapai 210.700 ton dengan jumlah tangkap yang dibolehkan 168.200 ton (DKP Maluku Tengah, 2013). Perikanan pelagis besar seperti cakalang, tuna, dan tongkol merupakaan komoditi perikanan yang memiliki nilai ekonomi yang relatif tinggi dibandingkan jenis ikan lainnya dan merupakan komoditas unggulan Kabupaten Maluku Tengah.

Nilai produksi ikan pelagis besar (cakalang, tuna, dan tongkol) pada tahun 2013 mencapai $74.185,4$ ton, nilai ini mengalami peningkatan dari tahun sebelumnya yakni 48.681 ton (DKP Maluku Tengah, 2013). Dari nilai tersebut Kecamatan Salahutu merupakan kecamatan yang memiliki produksi tertinggi. Produksinya tahun 2013 mencapai 11.260,9 ton. Ikan jenis ini merupakan salah satu sumber pendapatan penting bagi nelayan di Kecamatan Salahutu.

Desa Tial merupakan desa pesisir di Kecamatan Salahutu yang sebagian masyarakatnya bertumpu pada sektor perikanan, khususnya perikanan pelagis besar. Kegiatan eksploitasi dilakukan dengan alat tangkap pancing tegak dan pancing tonda.

Studi kelayakan merupakan suatu pertimbangan menerima atau menolak pelaksanaan suatu usaha. Pengertian layak dalam penilaian ini adalah manfaat (Benefit) yang diperoleh dari pelaksanaan usaha (Ibrahim, 2003).

Analisis kelayakan usaha perikanan tangkap ikan pelagis besar bertujuan untuk menilai sejauh mana manfaat secara finansial yang diterima melalui usaha tersebut sehingga dapat menjadi Informasi dalam rangka pengembangan alat tangkap dalam upaya meningkatkan produktivitas daerah dan peningkatan kesejahteraan nelayan. 


\section{METODE PENELITIAN}

Penelitian ini menggunakan metode deskriptif analitis dengan jenis metode survei (Nazir, 1999). Jenis data yang digunakan adalah data primer yang diperoleh melalui survei dan wawancara dengan nelayan responden.

Analisis data mencakup analisis kelayakan finansial. Kadariah (1986) menyatakan bahwa untuk mengevaluasi kelayakan finansial dapat digunakan kriteria investasi yang penting, yaitu Net Present Value (NPV), Net Benefit-Cost ratio, Internal Rate of Return, dan Payback Periods.

\section{(1) Net Present Value (NPV)}

NPV dari suatu usaha merupakan nilai sekarang (Present value) dari selisih antara benefit (manfaat) dengan cost (biaya) pada discount rate tertentu. NPV yaitu menunjukan kelebihan benefit (manfaat) dibandingkan dengan cost (biaya). (Pasaribu, 2005). Rumus untuk menghitung NPV adalah :

$$
N P V=\sum_{i=0}^{t=n} \frac{B t-C t}{(1+i)^{t}}
$$

Keterangan :

Bt $=$ Manfaat pada tahun ke $-t(R p)$

$\mathrm{t}$ = Biaya pada tahun ke $-\mathbf{t}(\mathbf{R p})$

$$
=\text { Tingkat bunga }(\%)
$$

$=$ Umur ekonomis

$=1,2,3, \ldots . n$

Apabila evaluasi suatu usaha dinyatakan layak maka nilai $N P V \geq 0$. Bila NPV $=0$, berarti proyek tersebut mengembalikan persis sebesar social opportunity cost of capital, dan bila NPV $<0$, maka proyek tersebut tidak layak.

(2) Net Benefit Cost Ratio

Net Benefit Cost Ratio adalah perbandingan antara jumlah NPV positif dengan jumlah NPV negatif. Hal ini menunjukan bahwa besarnya benefit berapa kali besarnya biaya dan investasi untuk memperoleh suatu manfaat.

Rumus untuk menghitung $\mathrm{Net} B / \mathrm{C}$ adalah:

$$
\operatorname{Net} B / C=\frac{\sum_{t=1}^{n} \frac{B_{i}-C_{t}}{(1+i)^{t}}}{\sum_{t=1}^{n} \frac{C_{t}-B_{t}}{(1+i)^{t}}}
$$

Kriteria :

- $\mathrm{B} / \mathrm{C}>1=$ usaha layak untuk dilaksanakan, NPV $>0$

- $\mathrm{B} / \mathrm{C}=\mathbf{1}=$ usaha layak dalam kondisi break event point
- $\mathrm{B} / \mathrm{C}<1=$ usaha tidak layak untuk dilaksanakan

(3) Internal Rate of Return (IRR)

IRR merupakan suku bunga maksimal untuk sampai kepada NPV bernilai sama dengan nol, jadi dalam keadaan untung rugi. IRR juga dianggap sebagai tingkat keuntungan atas investasi bersih dalam suatu proyek.

Rumus IRR adalah :

$$
I R R=i_{1}+\frac{N P V_{1}}{N P V_{1}-N P V_{2}}\left(i_{2}-i_{1}\right)
$$

Keterangan :

$i_{1}=$ Tingkat bunga yang menghasilkan

NPV positif

$i_{2}=$ Tingkat bunga yang menghasilkan NPVnegatif

$\mathrm{NPV}_{1}=\mathrm{NPV}$ pada tingkat bunga $\mathrm{i}_{1} \quad \mathrm{NPV}_{2}$

$=$ NPV pada tingkat bunga $i_{2}$

Proyek dikatakan layak jika IRR > dari tingkat suku bunga yang berlaku, sehingga jika IRR = tingkat bunga yang berlaku maka NPV dari proyek tersebut sama dengan nol. Jika IRR < dari tingkat bunga yang berlaku maka berarti NPV $<0$ berarti proyek tidak layak.

(4) Payback Periods (PP)

Payback Periods merupakan jangka waktu pengembalian modal investasi yang akan dibayarkan melalui keuntungan yang diperoleh suatu usaha. Semakin cepat waktu pengembalian, semakin baik untuk diusahakan. Adapun rumus yang digunakan menurut Pasaribu (2005) adalah :

$$
P P=\frac{I}{B_{t}}
$$

Keterangan :

$$
\begin{aligned}
& I=\text { Jumlah Investasi } \\
& B_{t}=\text { Net benefit rata-rata tiap tahun }
\end{aligned}
$$

\section{HASIL DAN PEMBAHASAN}

\subsection{Perikanan Pelagis Besar}

Kegiatan perikanan tangkap di Desa Tial merupakan salah satu aktivitas yang ditekuni oleh sebagian masyarakat secara turun temurun. Umumnya penangkapan ditujukan untuk menangkap ikan pelagis besar, seperti : tuna, cakalang, dan tongkol. Nelayan yang menangkap ikan pelagis besar menggunakan alat tangkap pancing tonda dan pancing tegak. 
Dengan armada yang mendominasi adalah kapal motor tempel yang berkekuatan 15 PK.

Aktivitas penangkapan oleh nelayan di Desa Tial dilakukan mulai pukul 3.00 WIT-15.000 WIT. Adapun daerah fishing groundnya antara lain Perairan Selat Haruku, Laut Seram, dan Laut Banda. Sebelum menuju fishing ground nelayan biasanya mencari umpan terlebih dahulu. Umpan yang dimaksud adalah cumicumi dan beberapa jenis ikan pelagis kecil. Selain itu juga nelayan juga menggunakan beberapa jenis umpan buatan, misalnya umpan yang terbuat dari plastik, umpan yang terbuat dari bahan sifon yang dicampur dengan rambut manusia. Nelayan juga menggunakan alat bantu penangkapan seperti layangan maupun rumpon. Menurut Subani dan Barus (1989), beberapa cara mendapatkan kawanan ikan sebelum penangkapan ikan dilakukan adalah menggunakan alat bantu penangkapan seperti rumpon dan sinar lampu ( light fishery). Selain itu, Subani (1986) dan Gunarso (1980) dalam Kurnia et al (2012) menyatakan bahwa rumpon merupakan tempat berlindung dan mencari makan ikan-ikan pelagis, seperti layang, madidihang, tuna mata besar, tuna sirip kuning, tongkol dan tenggiri.

\subsection{Pendapatan Nelayan}

Pendapatan nelayan pancing tegak dan pancing tonda di Desa Tial sangat dipengaruhi oleh musim. Musim dapat mempengaruhi banyaknya ikan hasil tangkapan. Sedangkan nilai jual ikan rata-rata per- kg di Desa Tial setiap musim sama. Berikut ini disajikan pendapatan bersih nelayan usaha penangkapan ikan pelagis besar di Desa Tial.

Tabel 1. Pendapatan Bersih per Jenis Alat Tangkap di Desa Tial

\begin{tabular}{llcc}
\hline No & $\begin{array}{c}\text { Jenis } \\
\text { Alat Tangkap }\end{array}$ & $\begin{array}{c}\text { Pendapatan Bersih Rata- } \\
\text { Rata per Trip (Rp) }\end{array}$ & $\begin{array}{c}\text { Pendapatan Bersih Rata- } \\
\text { Rata per Tahun (Rp) }\end{array}$ \\
\hline 1 & Pancing Tegak & $2.725 .778,27$ & $663.339 .186,43$ \\
2 & Pancing Tonda & 945.731 & $232.147 .266,67$
\end{tabular}

Sumber : Data Primer Diolah, 2016

Berdasarkan Tabel di atas pendapatan bersih dari kedua jenis alat tangkap, memperlihatkan pancing tegak memberikan pendapatan bersih tertinggi baik pendapatan bersih per trip maupun pendapatan bersih per tahun, yaitu Rp.2.725.778,27 /trip dan Rp.663.339.186,43/tahun. Pendapatan ini diperoleh dari tiga musim penangkapan, yaitu musim puncak (banyak ikan), musim pancaroba, dan musim paceklik (sedikit ikan ). Pada musim paceklik nelayan biasanya memperoleh hasil tangkapan yang sedikit sedangkan biaya operasional yang harus dikeluarkan cukup tinggi sehingga mempengaruhi pendapatan nelayan.

3.3. Analisis Kelayakan Usaha Perikanan Tangkap Ikan Pelagis Besar di Desa Tial Analisis kelayakan dilakukan untuk melihat apakah usaha tersebut layak atau tidak untuk diteruskan (menguntungkan/ merugikan).

Analisis usaha ikan pelagis besar di Desa Tial dilakukan dengan menghitung kelayakan finansial masing-masing alat tangkap. Analisis kelayakan usaha dengan menggunakan kriteria Net Present Value (NPV) , Benefit Cost Ratio (B/C ratio), Internal Rate of Return (IRR), dan payback periods (Pasaribu, 2005). Perhitungan analisis penangkapan dilakukan selama 10 tahun dengan discount factor $\mathbf{1 0} \%$ sesuai dengan pendapat Gittinger (1986) bahwa untuk Negara-negara sedang berkembang pengukuran suatu proyek usaha menggunakan discount factor diasumsikan $8 \%$ $15 \%$ dalam nilai yang sebenarnya.

Hasil analisis kelayakan usaha dari masing-masing alat tangkap dapat disajikan pada tabel berikut :. 
Tabel 2 . Nilai Kriteria Investasi Usaha Perikanan Tangkap di Desa Tial

\begin{tabular}{|c|c|c|c|c|c|c|}
\hline \multirow{2}{*}{ No } & \multirow{2}{*}{$\begin{array}{c}\text { Jenis Alat } \\
\text { Tangkap }\end{array}$} & \multicolumn{4}{|c|}{ Kriteria Investasi } & \multirow{2}{*}{ Kelayakan } \\
\hline & & $N P V(R p)$ & $\begin{array}{c}\text { Net } B / C \\
\text { ratio (\%) }\end{array}$ & $\begin{array}{l}\text { IRR } \\
(\%)\end{array}$ & $P P$ & \\
\hline 1 & Pancing Tegak & 7.263.992.073,37 & 8,32 & 38,15 & 1 Tahun 3 bulan & Layak \\
\hline 2 & Pancing Tonda & 1.012.791.527,69 & 1,16 & 34,11 & 1 Tahun 1 bulan & Layak \\
\hline
\end{tabular}

Sumber : Data Primer Diolah, 2016

Analisis kriteria investasi untuk alat tangkap pancing tegak dan pancing tonda memperlihatkan usaha pancing tegak merupakan usaha yang paling layak untuk dikembangkan berdasarkan nilai NVP, yaitu Rp. 7.263.992.073,37 artinya nilai saat ini dari keuntungan yang akan diperoleh selama umur usaha 10 tahun di masa yang akan datang $\mathbf{R p}$. 7.263.992.073,37. Hal ini menunjukan usaha ini layak untuk diteruskan. Untuk nilai $B / C$ rationya adalah 8,32 , artinya manfaat yang diperoleh 8,32 kali lipat dari biaya yang dikeluarkan selama umur usaha 10 tahun dengan suku bunga $10 \%$. Hasil perhitungan nilai IRR sebesar $38,15 \%$, artinya tingkat pengembalian internal yang dihasilkan dari investasi usaha alat tangkap pancing tegak lebih besar nilainya dibandingkan dengan bunga pinjaman bank sebesar $10 \%$ sehingga usaha ini dinilai layak dan menguntungkan untuk dikembangkan. Sedangkan dari hasil perhitungan payback period diketahui bahwa waktu yang diperlukan untuk dapat mengembalikan seluruh biaya investasi yang dikeluarkan adalah 1 tahun 3 bulan.

Analisis kriteria investasi alat tangkap pancing tonda juga menunjukan usaha tersebut layak untuk diteruskan. Sedangkan nilai payback period menunjukan alat tangkap pancing tonda yang paling cepat jangka waktu pengembalian modal investasi dibandingkan alat tangkap pancing tegak.

\section{PENUTP}

Berdasarkan hasil analisis finansial dapat disimpulkan bahwa :

1. usaha penangkapan ikan pelagis besar di Desa Tial dengan alat tangkap pancing tegak layak diteruskan berdasarkan kriteria NPV Rp. 7.263.992.073,37, Net B/C ratio 8,32, IRR 38,15\% dan Payback period 1 tahun 3 bulan.

2. Usaha alat tangkap pancing tonda juga layak untuk diteruskan. Nilai NVP Rp. 1.012.791.527,69, Net $\mathrm{B} / \mathrm{C}$ ratio 1,16, IRR $34,11 \%$ dan Payback period 1 tahun 1 bulan

\section{DAFTAR PUSTAKA}

Dinas Perikanan dan Kelautan Kabupaten Maluku Tengah. 2013. Laporan Tahunan Statistik Perikanan Tahun 2013. Masohi Maluku Tengah.

Gittinger,P.J. 1986. Analisa Ekonomi Proyek-Proyek Pertanian. The Johns Hopkins University Press. Penerjemah Sutomo S. \&Mangiri K. Penerbit UI Press, Jakarta

Ibrahim,Y. 2003. Studi Kelayakan Bisnis. Edisi Revisi. PT. Rineka Cipta, Jakarta.

Kadariah. 1986. Evaluasi Proyek: Analisis Ekonomi. Lembaga Penerbit Fakultas Ekonomi Universitas Indonesia, Jakarta.

Kurnia, M., M. Palo, dan Jumsurizal. 2012. Produktivitas Pancing Ulur Untuk Penangkapan Ikan Tenggiri (Scomberomorus commerson) di Perairan Pulau Tambelan Kepulauan Riau. Makalah Seminar Internasional/Nasional I Industrialisasi Perikanan dan Kelautan. Universitas Riau.

Nazir,M. 1999. Metode Penelitian. Ghalia Indonesia, Jakarta.

Pasaribu, A.M., D, Yusuf., dan Amiluddin. 2005. Perencanaan dan Evaluasi Proyek Perikanan. Hasanuddin University Press, Makassar.

Subani dan Barus. 1989. Alat Penangkapan Ikan dan Udang Laut di Indonesia. Departemen Pertanian, Jakarta. 